University of Wollongong

Research Online

Faculty of Informatics - Papers (Archive)

Faculty of Engineering and Information

Sciences

$16-7-2007$

\title{
Analysis of Network Asymmetry of Interconnected 66kV Sub-transmission Systems in relation to Voltage Unbalance
}

Prabodha Paranavithana

University of Wollongong, ptp123@uow.edu.au

S. Perera

University of Wollongong, sarath@uow.edu.au

Danny Sutanto

University of Wollongong, soetanto@uow.edu.au

Follow this and additional works at: https://ro.uow.edu.au/infopapers

Part of the Physical Sciences and Mathematics Commons

\section{Recommended Citation}

Paranavithana, Prabodha; Perera, S.; and Sutanto, Danny: Analysis of Network Asymmetry of Interconnected 66kV Sub-transmission Systems in relation to Voltage Unbalance 2007.

https://ro.uow.edu.au/infopapers/607

Research Online is the open access institutional repository for the University of Wollongong. For further information contact the UOW Library: research-pubs@uow.edu.au 


\title{
Analysis of Network Asymmetry of Interconnected 66kV Sub-transmission Systems in relation to Voltage Unbalance
}

\author{
Abstract \\ The levels of voltage unbalance that exist in some interconnected sub-transmission networks in Australia \\ has been observed to be above the code requirements (e.g. $1 \%$ in Victoria). There is a perception that \\ these high levels arise as a result of asymmetrical loads. However, it is identified that the network \\ asymmetry in relation to transmission lines also play a significant role in the lead up to this situation, \\ employing an interconnected $66 \mathrm{kV}$ sub-transmission system as the study case. The individual \\ transmission lines of the study network are analysed in order to observe their possible influence arising \\ as a result of line impedance characteristics and line loading levels. A methodology is developed to \\ quantify the contribution of individual transmission lines to the role played by the network at nodal level. \\ The leading contributors to the problem in the study network are explored employing the proposed \\ approach. \\ Disciplines \\ Physical Sciences and Mathematics

\section{Publication Details} \\ This conference paper was originally published as Paranavithana, P, Perera, S, and Sutanto, D, Analysis of \\ Network Asymmetry of Interconnected 66kV Sub-transmission Systems in relation to Voltage Unbalance, \\ IEEE PowerAfrica 2007: Conference and Exposition, South Africa, 16-20 July, 1-8.
}




\title{
Analysis of Network Asymmetry of Interconnected 66kV Sub-transmission Systems in relation to Voltage Unbalance
}

\author{
Prabodha Paranavithana, Sarath Perera and Danny Sutanto \\ Integral Energy Power Quality and Reliability Centre \\ University of Wollongong \\ NSW 2522, Australia \\ Phone: +61 024221 3575, Email: ptp123@uow.edu.au
}

\begin{abstract}
The levels of voltage unbalance that exist in some interconnected sub-transmission networks in Australia has been observed to be above the code requirements (e.g. $1 \%$ in Victoria). There is a perception that these high levels arise as a result of asymmetrical loads. However, it is identified that the network asymmetry in relation to transmission lines also play a significant role in the lead up to this situation, employing an interconnected $66 \mathrm{kV}$ sub-transmission system as the study case. The individual transmission lines of the study network are analysed in order to observe their possible influence arising as a result of line impedance characteristics and line loading levels. A methodology is developed to quantify the contribution of individual transmission lines to the role played by the network at nodal level. The leading contributors to the problem in the study network are explored employing the proposed approach.
\end{abstract}

\section{INTRODUCTION}

Excessive voltage unbalance levels has become a power quality problem of concern in some networks in Australia, as it leads problems such as overheating of three-phase induction motors, generation of non-characteristic harmonics by threephase power converters and additional power losses in power networks. Uneven distribution of single phase loads and asymmetrical transmission line impedances possibly caused by incomplete transposition are the two major sources of voltage unbalance.

The National Electricity Code (NEC) of Australia [1] specifies the average voltage unbalance to be limited at $0.5 \%$ for systems operating at or above $100 \mathrm{kV}, 1.3 \%$ for systems operating between $10 \mathrm{kV}$ and $100 \mathrm{kV}$ and $2.0 \%$ for $10 \mathrm{kV}$ and lower voltage systems, when determined over a 30minute averaging period. Concurrently, Australian electricity distributors are obliged to limit the voltage unbalance at the point of common coupling to a customer's three-phase electrical installation as stipulated in electricity distribution codes. As an example, this limit is $\leq 1 \%$ with excursions up to $2 \%$ for a total of 5 minutes in every 30 -minute period for Victorian distributors [2].

Some electricity distributors in Australia are facing difficulties in maintaining the levels of voltage unbalance in their high voltage networks in order to satisfy the electricity distribution code requirements. As an example, the $66 \mathrm{kV}$ subtransmission system under study (whose voltage unbalance limit is at $1 \%$ ), is experiencing voltage unbalance levels up to $2 \%$ at some zone substations (ZS) during peak demand periods. There is the perception that this occurs primarily due to asymmetry associated with loads where not much attention has been given to the possible contribution from untransposed transmission lines, since the effect of transposition is not well established at sub-transmission voltage levels. In addition, the need for careful modelling of system components and lack of widespread availability and use of proper unbalanced load flow programs for analysis of asymmetrical systems have aggravated the situation.

A generalised three-phase power flow program in phase domain has been developed in order to use as the tool for analysing the role of sub-transmission lines in relation to voltage unbalance. The impact of sub-transmission lines is investigated as a study case employing an interconnected $66 \mathrm{kV}$ sub-transmission system. The individual transmission lines of the study network are analysed in detail with the objective of understanding their influence by considering their impedance characteristics and operational aspects. An approach is developed in order to quantify the contribution of individual transmission lines to the problem at nodal level based on the concept of linearity in relation to the operation of negative sequence networks. The proposed approach is employed to the study network, and thus the transmission lines which lead up to the problem are explored.

The paper is organised as follows: Section II briefly describes the work behind the development of the three-phase power flow program. The impact of the transmission lines on the problem of voltage unbalance in the study network is presented in Section III. The approaches and the results of the analysis of individual transmission lines are discussed in Section IV. Section V gives the methodology proposed to quantify the contribution of individual transmission lines to the problem at nodal level and the results of this quantification process in relation to the study network. Section VI summarises the results and gives broad conclusions. 


\section{THREE-PHASE POWER FLOW}

The well known method of analysing unbalanced power system problems is the three-phase power flow which incorporates three-phase modelling of power system components. The available literature [3]-[7] proposes two basic approaches for three-phase power flow analysis, which are based on symmetrical components and phase co-ordinates respectively. However, since the approach based on phase co-ordinates has been identified as the best way to represent three-phase power system components in comparison to symmetrical components [4].

Three-phase synchronous machines are modelled as positive sequence voltage sources behind the generator admittance matrix in order to take different machine responses to positive, negative and zero sequence current injections into account [6][7]. Passive loads are represented using exponential load models [8] as single phase branches between two nodes. Asymmetrical electromagnetic coupling is incorporated in modelling the overhead transmission lines [9].

The load flow constraints for system components are expressed at component level (concept of component level power flow constraints), instead of traditional nodal level constraints. This new concept allows development of a generalised three-phase power flow program which provides the flexibility to incorporate numerous component connections [6]-[7]. Subsequently the interaction between network and system components with power flow constraints (loads and generators) are obtained by component branch currents using $[\mathrm{I}]=[\mathrm{Y}][\mathrm{V}]$. The solution is established employing the Newton-Raphson iterative technique. Further details in relation to the developed three-phase power flow program can be found in [10].

\section{IMPACT OF 66kV TRANSMISSION LINES ON VOLTAGE UNBALANCE - CASE STUDY}

The $66 \mathrm{kV}$ sub-transmission system under study as shown in Fig. 1 is energised at ZS1 (bulk supply point) where the voltage unbalance has been measured to be negligible. Most of the transmission lines of the network are longer than $50 \mathrm{~km}$ and are not systematically transposed. The network supplies major customers including irrigators who use three-phase induction motor pump systems.

Despite the fact that the voltage unbalance at ZS1 is negligible, the levels of voltage unbalance that exist at downstream load buses (ZS7, ZS8 and ZS9) have been noted to exceed $2 \%$ while there are significant levels $(1.2 \%)$ at ZS2 and ZS4 during peak demand periods, although the sub-transmission authority is bound to limit these levels at $1 \%$ as stipulated in the applicable electricity distribution code. Initial studies have revealed that significant degree of load asymmetry existed at ZS7 and ZS8. The voltage unbalance in the network has reduced after balancing the loads at these buses, yet the subsequent levels have been noted to be excessive.

In order to understand the role played by the asymmetry associated with the network, its impact is established in terms of voltage unbalance factor (VUF) at various ZSs employing the developed three-phase power flow program. This is accomplished by synthesising the actual network operation, while maintaining the load in the system balanced. Hence, the negative sequence voltage which appears at various ZSs arises as a result of the transmission lines. Fig. 2 illustrates the results obtained with respect to a selected time stamp which lies within the system peak. It can be seen from the above results that the asymmetry of the network alone introduces excessive levels of voltage unbalance at the ZSs located in the central part (ZS6 and ZS7) and the downstream (ZS8 and ZS9) of the network. The influence of the transmission lines is seen to be considerable even at the most upstream ZSs (ZS2 and 7S4) of the network.

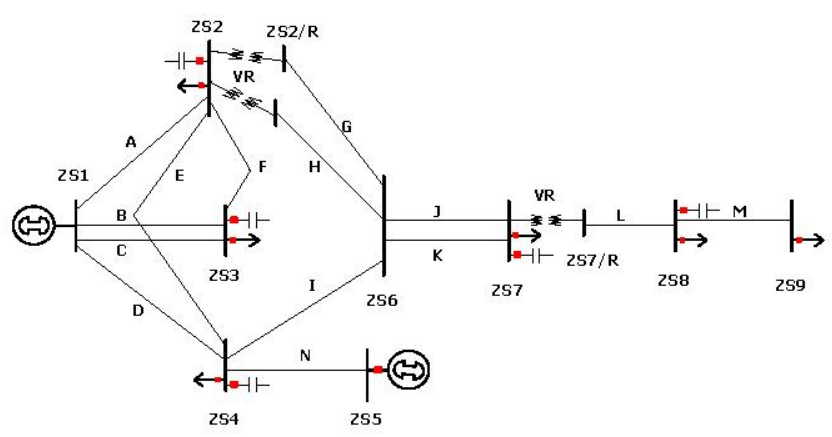

Fig. 1. Study network

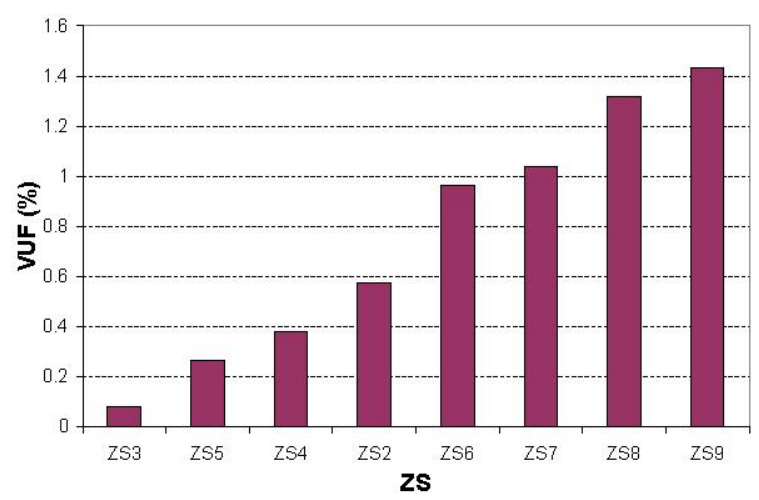

Fig. 2. VUF at various ZSs caused by the asymmetry of the network

\section{ANALYSIS OF TRANSMISSION LINES}

\section{A. Study $I$}

The objective of the study presented in this section is to identify the individual influence of the transmission lines 
in relation to voltage unbalance without introducing any effect of their interaction in a network environment and other sources of voltage unbalance, and hence to investigate the impact of impedance characteristics of the lines. Hence, each transmission line is studied as a single radial line which is excited by balanced three-phase voltages $(66 \mathrm{kV})$ supplying a balanced PQ type load as shown in Fig. 3. Thus, the only source of negative sequence voltage at the receiving end $\left(V_{2}\right.$, receiving end $)$ is the asymmetry of the transmission line under study. The voltage $V_{2}$, receiving end can be expressed as given by (1) employing symmetrical components:

$$
V_{2, \text { receiving end }}=-\left(Z_{-0} I_{0}+Z_{-+} I_{+}+Z_{--} I_{-}\right)
$$

where,

subscripts:

$x$ and $y$ refer to zero $(0)$, positive $(+)$, negative $(-)$ sequences

$Z_{x y}$ - mutual impedance between $\mathrm{x}$ and $\mathrm{y}$ sequence networks of the transmission line, when $x \neq y$

$Z_{x y}$ - self impedance of sequence network $x(=y)$ of the transmission line

$I_{x}$ - line current of sequence network $x$ of the transmission line

Since, $Z_{--}=Z_{++}$for transmission lines and both $Z_{-0}$ and $I_{0}$ are negligible for three-wire systems, (1) can be simplified as:

$$
V_{2, \text { receiving end }}=-\left(Z_{-+} I_{+}+Z_{++} I_{-}\right)
$$

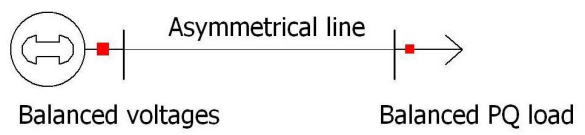

Fig. 3. A radial transmission line

By varying $\left|I_{+}\right|$of (2) which is the independent variable (0.9 lagging power factor is assumed), its impact on $\left|I_{-}\right|$and $\mid V_{2}$, receiving end $\mid$ is established.

As shown in Fig. 4, $\left|I_{-}\right|$is proportional to $\left|I_{+}\right|$at lower values of $\left|I_{+}\right|$(light loading levels), where the proportionality constant is unique for each line. Table 1 gives both magnitude and phase angle of the the impedances $Z_{-+}$of the transmission lines. Considering the gradients of the specific variations, it can be identified that the proportionality constant is determined by $\left|Z_{-+}\right|$.

Fig. 4 also illustrates that the variation of $\left|I_{-}\right|$with $\left|I_{+}\right|$of some transmission lines becomes non-linear at higher values of $\left|I_{+}\right|$(heavy loading levels). Table 2 comments on this variations, highlighting the characteristics of the respective impedance matrices. Following these observations, it can be identified that $\left|I_{-}\right|$can be expressed as a higher order equation of $\left|I_{+}\right|$at heavy loading levels, where the coefficients of the independent variable $\left(\left|I_{+}\right|\right)$is seen to depend on both impedances $\left|Z_{-+}\right|$and $Z_{++}$.

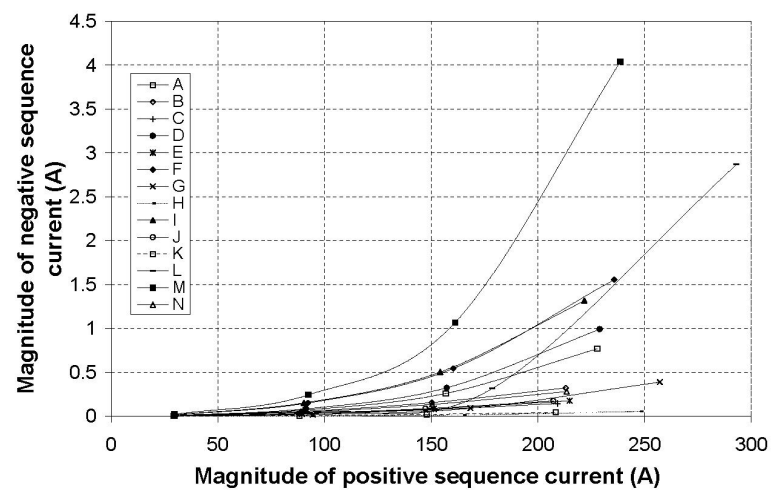

Fig. 4. Variation of $\left|I_{-}\right|$with $\left|I_{+}\right|$for individual lines

Table 1. Impedances $Z_{-+}$of the transmission lines

\begin{tabular}{c|c}
\hline $\begin{array}{c}\text { Transmission } \\
\text { line }\end{array}$ & $\begin{array}{c}\text { Magnitude }(\Omega) \\
\text { and angle (deg.) }\end{array}$ \\
\hline \hline $\mathrm{M}$ & $1.91,55$ \\
\hline $\mathrm{I}$ & $1.40,30$ \\
\hline $\mathrm{F}$ & $1.25,30$ \\
\hline $\mathrm{D}$ & $0.74,178$ \\
\hline $\mathrm{A}$ & $0.62,84$ \\
\hline $\mathrm{B}$ & $0.52,30$ \\
\hline $\mathrm{N}$ & $0.45,23$ \\
\hline $\mathrm{J}$ & $0.31,148$ \\
\hline $\mathrm{L}$ & $0.30,131$ \\
\hline $\mathrm{E}$ & $0.27,65$ \\
\hline $\mathrm{C}$ & $0.25,336$ \\
\hline $\mathrm{G}$ & $0.14,34$ \\
\hline $\mathrm{K}$ & $0.08,121$ \\
\hline $\mathrm{H}$ & $0.03,47$
\end{tabular}

Fig. 5 shows that $\mid V_{2}$, receiving end $\mid$ varies linearly with $\left|I_{+}\right|$at light loading levels for all transmission lines. Fig. 5 and Table 1 verify that the gradient of a specific relationship is equal to the respective impedance $\left|Z_{-+}\right|$. That is, $V_{2}$, receiving end can be quantified using (3), and the influence of the component $Z_{++} I_{-}$component seems to be quite small due to insignificant levels of $\left|I_{-}\right|$at light loading conditions.

$$
V_{2, \text { receiving end }} \approx-\left(Z_{-+} I_{+}\right)
$$

Fig. 5 also illustrates that the variation of $\mid V_{2}$, receiving end $\mid$ with $\left|I_{+}\right|$becomes non-linear only for line $\mathrm{M}$ which has an extra large $\left|Z_{-+}\right|(1.91 \Omega)$ and a large $\left|Z_{++}\right|(29.9 \Omega)$, and line $\mathrm{L}$ which has a small $\left|Z_{-+}\right|(0.3 \Omega)$ and a very large $\left|Z_{++}\right|(41 \Omega)$ at heavy loading levels. Hence, (3) can be used to quantify $V_{2}$, receiving end with acceptable degree 
Table 2. Comments on variation of $\left|I_{-}\right|$with $\left|I_{+}\right|$at heavy loading levels and characteristics of respective impedance elements

\begin{tabular}{c|c|c|c}
\hline $\begin{array}{c}\text { Transmission } \\
\text { line/s }\end{array}$ & $\begin{array}{c}\text { level / non-linearity } \\
\text { of } I_{-}\end{array}$ & $\left|Z_{-+}\right|$ & $\left|Z_{++}\right|$ \\
\hline \hline $\begin{array}{c}\text { B, N, J, E, } \\
\text { C and K }\end{array}$ & Low / Very low & Very small to moderate & Small \\
\hline H & Low / Very low & Very small $(0.03 \Omega)$ & Large $(28.8 \Omega)$ \\
\hline G & Low / Moderate & Very small $(0.14 \Omega)$ & Large $(32.5 \Omega)$ \\
\hline I, F, D & High / Moderate & Large to very large & Moderate \\
and A & & $(0.62 \Omega-1.4 \Omega)$ & $(19.98 \Omega-24.81 \Omega)$ \\
\hline M & Very high / Very high & Extra large $(1.91 \Omega)$ & Large $(29.9 \Omega)$ \\
\hline L & High / Very high & Small $(0.3 \Omega)$ & Very large $(41 \Omega)$ \\
\hline
\end{tabular}

of accuracy even at heavy loading levels for almost all the transmission lines. However, the accuracy seems to drop off for transmission lines which have large $\left|Z_{++}\right|$together with atleast small $\left|Z_{-+}\right|(0.3 \Omega)$, since $Z_{++} I_{-}$component cannot be ignored for such lines at heavy loading conditions.

Based on the above observations, it can be seen that $\left|Z_{-+}\right|$can be employed to assess the degree of asymmetry associated with individual transmission lines in relation to voltage unbalance in general. Therefore, the transmission lines of the study network can be ranked based on their degree of asymmetry, as given in Table 3 .

\section{B. Study II}

The transmission lines with significant level of asymmetry acting on their own cannot be identified as the major sources of voltage unbalance, as there can be other factors which determine the influence of transmission lines when they are operating in a network environment. Hence, this section analyses the individual transmission lines in relation to their impact on voltage unbalance when they operate in the interconnected network environment.

In this study, the transmission line whose influence to be observed is kept with its actual construction while the other lines are hypothetically transposed, when the network is operating under its actual conditions, however with balanced PQ type loads. Hence, the only source of voltage unbalance in the network is the "transmission line under observation", and its impact is then obtained in terms of VUF at various ZSs.

Three-phase power flow establishes $I_{+}$in the lines primarily depending on the loading conditions, $Z_{++}$and the configuration of the network (positive sequence variables are negligibly affected by the changes in the negative sequence network), and $I_{-}$in the lines which is caused by the asymmetry $\left(\left|Z_{-+}\right|\right)$of the "line under observation". The flow of $I_{-}$ in lines results in negative sequence voltage at ZSs. Negative sequence voltage at the receiving end of the "transmission line under observation" is given by (4) and of other hypothetically transposed lines $\left(Z_{-+}=0\right)$ is given by (5).

Fig. 6 illustrates the level of influence established for individual transmission lines at different ZSs. These results suggest that lines I, F, A, D and J are the sources which introduce significant levels of influence on the network, while lines $\mathrm{B}, \mathrm{N}, \mathrm{C}, \mathrm{L}$ and $\mathrm{M}$ are the minor sources of voltage unbalance. The levels of influence introduced by lines E, G, H and $\mathrm{K}$ are negligible. It is interesting to note that line $\mathrm{M}$ which carries a very low level of $I_{+}$under operating conditions has not been a major source although it is the most asymmetrical line of the network, whereas line J which carries the highest level of $I_{+}$under operating conditions has been a major source although it has a low level of asymmetry. Table 4 summarises these results highlighting some important factors which may determine the levels of influence of individual lines. From these observations the level of $\left|I_{+}\right|$prevailing under operating conditions and the respective $\left|Z_{-+}\right|$can be identified as the primary factors which determine the degree of influence introduced by an asymmetrical transmission line.

$$
\begin{gathered}
V_{2, \text { receiving end }}=V_{2, \text { sending end }}-\left(Z_{-+} I_{+}+Z_{++} I_{-}\right) \\
V_{2, \text { receiving end }}=V_{2, \text { sending end }}-Z_{++} I_{-}
\end{gathered}
$$

Table 3. Ranking of the transmission lines based on degree of asymmetry

\begin{tabular}{c|c|c}
\hline Transmission line/s & $\left|Z_{-+}\right|(\Omega)$ & Rank \\
\hline \hline M & $\sim 2.0$ & Extraordinarily High \\
\hline I and F & $\sim 1.3$ & Very high \\
\hline D and A & $\sim 0.65$ & High \\
\hline B and N & $\sim 0.5$ & Moderate \\
\hline J, L, E and C & $\sim 0.3$ & Low \\
\hline G, K and H & $\sim 0.1$ & Very low \\
\hline
\end{tabular}

\section{QUANTIFICATION OF CONTRIBUTION FROM INDIVIDUAL TRANSMISSION LINES AT NODAL LEVEL}

The major sources of voltage unbalance in the study network as identified in Section IV above may not be the leaders 
Table 4. Summary of levels of influence of individual transmission

lines and respective impedance and operating characteristics

\begin{tabular}{c|c|c|c}
\hline $\begin{array}{c}\text { Transmission } \\
\text { line }\end{array}$ & $\left|Z_{-+}\right|$ & $\begin{array}{c}\text { Level } \\
\text { of }\left|I_{+}\right|\end{array}$ & $\begin{array}{c}\text { Level of } \\
\text { influence }\end{array}$ \\
\hline \hline M & Extra large $(\sim 2 \Omega)$ & Very low $(\sim 15 \mathrm{~A})$ & Low \\
\hline F and I & Very large $(\sim 1.3 \Omega)$ & High $(\sim 150 \mathrm{~A})$ & High \\
\hline A and D & Large $(\sim 0.65 \Omega)$ & Very High $(\sim 200 \mathrm{~A})$ & High \\
\hline $\mathrm{B}$ and N & Moderate $(\sim 0.5 \Omega)$ & High & Low \\
\hline J & Small $(\sim 0.3 \Omega)$ & Extra High $(\sim 250 \mathrm{~A})$ & High \\
\hline L & Small & Low $(\sim 75 \mathrm{~A})$ & Low \\
\hline E & Small & Low & Very low \\
\hline $\mathrm{C}$ & Small & Very high & Low \\
\hline $\mathrm{G}, \mathrm{H}$ and K & Very Small $(\sim 0.1 \Omega)$ & High & Very Low \\
\hline
\end{tabular}

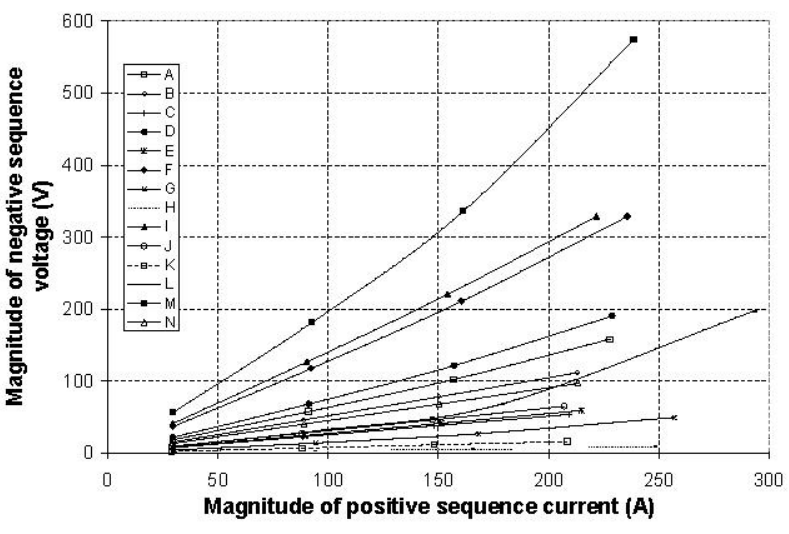

Fig. 5. Variation of $\mid V_{2}$, receiving end $\mid$ with $\left|I_{+}\right|$for individual lines

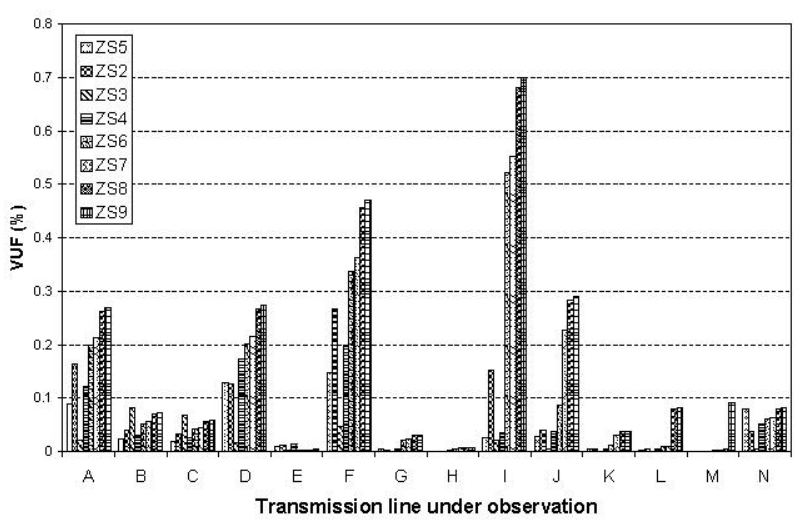

Fig. 6. VUF caused by individual transmission lines at different ZSs of the problem when all individual influences are combined together to form the actual network environment, since the phase angles of separate effects can play a role in determining the resultant influence at a node. Hence, a methodology has to be developed in order to quantify the contribution from the transmission lines to voltage unbalance, and thus allowing identification of the transmission lines which lead up to the problem.

The operation of the negative sequence network of the study system (with balanced loading conditions) is observed to be linear. That is, the resultant negative sequence current vector in a selected transmission line caused by the asymmetry of the network is equal to the vector addition of negative sequence current components caused by individual transmission lines in the selected line (Appendix A), as expressed by (6):

$$
I_{-, X}=\sum I_{-, X / Y}
$$

where,

$X$ - represents the selected transmission line

$I_{-, X}$ - resultant negative sequence current vector in transmission line $\mathrm{X}$

$Y$ - represents an asymmetrical transmission line of the network

$I_{-, X / Y}$ - negative sequence current vector caused by transmission line $\mathrm{Y}$ in transmission line $\mathrm{X}$

Further, the resultant negative sequence voltage vector at a selected ZS caused by the asymmetry of the network is equal to the vector addition of negative sequence voltage components caused by individual transmission lines at the selected ZS (Appendix B), as expressed by (7):

$$
V_{2, Z S X}=\sum V_{2}, Z S X / Y
$$

where,

$Z S X$ - represents the selected $\mathrm{ZS}$

$V_{2, Z S X}$ - resultant negative sequence voltage vector at ZS X 
$Y$ - represents an asymmetrical transmission line of the network

$V_{2, Z S X / Y}$ - negative sequence voltage vector caused by transmission line $\mathrm{Y}$ at $\mathrm{ZS} \mathrm{X}$

Hence, the negative sequence voltage at a ZS as expressed by (4) can be expanded as given by ( 8 ) employing the linearity of the operation of the negative sequence network.

$$
\begin{aligned}
V_{2, \text { receiving end }=} & V_{2, \text { sending end }}-Z_{-+, X} I_{+, X} \\
& -Z_{++, X}\left(I_{-}, X / A+I_{-}, X / B\right. \\
& \left.+\ldots+I_{-}, X / X+\ldots+I_{-}, X / N\right)
\end{aligned}
$$

where,

$\mathrm{X}$ - denotes a transmission line which connects two ZSs

$Z_{-+, X^{-}}$mutual impedance between negative and positive sequence networks of transmission line $\mathrm{X}$

$Z_{++, X^{-}}$self impedance of positive sequence network of transmission line $\mathrm{X}$

$I_{+, X}$ - positive sequence line current in transmission line $\mathrm{X}$

For ZSs which are directly connected to the bulk supply point $\left(1^{\text {st }}\right.$ level ZSs) where the three-phase voltages are balanced, $V_{2}$, sending end is zero. Therefore the negative sequence voltage at these ZSs can be expressed by (9).

$$
\begin{aligned}
& V_{2,1^{\text {st }} \text { level }}=-Z_{-+, X_{1}} I_{+, X_{1}}-Z_{++, X_{1}}\left(I_{-}, X_{1} / A\right. \\
& +I_{-}, X_{1} / B+\ldots+I_{-,} X_{1} / X_{1} \\
& \left.+\ldots+I_{-}, X_{1} / N\right)
\end{aligned}
$$

where,

$X_{1}$ - denotes a transmission line which connects the bulk supply point and a $1^{\text {st }}$ level ZS

The voltage component expressed by $-\left(Z_{++, X_{1}} I_{-}, X_{1} / Y\right)$ is the negative sequence voltage vector caused by line $\mathrm{Y}$ at the $\mathrm{ZS}$ where $\mathrm{Y}$ represents $\mathrm{A}, \mathrm{B}, \ldots ., \mathrm{N}$ and $Y \neq X_{1}$, as given by (10). When line $\mathrm{Y}$ represents line $X_{1}$ (i.e. $Y=X_{1}$ ), then the negative sequence voltage vector caused by line $\mathrm{Y}$ at the ZS will be given by (11).

$$
\begin{aligned}
& V_{2,1^{\text {st }} \text { level } / Y}=-\left(Z_{++, X_{1}} I_{-}, X_{1} / Y\right), \quad Y \neq X_{1} \\
& V_{2,1^{\text {st }} \text { level } / Y}=-\left(Z_{-+, Y} I_{+, Y}+\right. \\
& \left.Z_{++, Y} I_{-, Y / Y}\right), \quad Y=X_{1}
\end{aligned}
$$

The negative sequence voltage vector introduced by line $Y$ at a ZS which is connected to a $1^{\text {st }}$ level ZS ( $2^{\text {nd }}$ level ZS) becomes $-\left(Z_{++, X_{1}} I_{-, X_{1} / Y}+Z_{++, X_{2}} I_{-, X_{2} / Y}\right)$, for $Y \neq$ $X_{1}, X_{2}$, as given by (12), where $X_{2}$ denotes a transmission line which connects $1^{\text {st }}$ and $2^{\text {nd }}$ level ZSs.

$$
\begin{aligned}
V_{2,2^{\text {nd }} \text { level } / Y=}= & -\left(Z_{++, X_{1}} I_{-, X_{1} / Y}+\right. \\
& \left.Z_{++, X_{2}} I_{-, X_{2} / Y}\right), \quad Y \neq X_{1}, X_{2}
\end{aligned}
$$

Generally, the negative sequence voltage vector induced by line $\mathrm{Y}$ at a $n^{\text {th }}$ level ZS can be written in the form given by (13) when Y does not represent $X_{1}, X_{2}, \ldots, X_{n}$.

$$
\begin{aligned}
V_{2, n^{\text {th }} \text { level } / Y=}= & \left(Z_{++, X_{1}} I_{-, X_{1} / Y}+Z_{++, X_{2}} I_{-, X_{2} / Y}\right. \\
& \left.+\ldots .+Z_{++, X_{n}} I_{-, X_{n} / Y}\right) \\
& Y \neq X_{1}, X_{2}, \ldots, X_{n}
\end{aligned}
$$

Let,

$\left|V_{2, Z S X}\right| \angle \theta_{Z S X} X$ - resultant negative sequence voltage vector at $\mathrm{ZS} \mathrm{X}$ and,

$\left|V_{2, Z S X / Y}\right| \angle \theta_{Z S X / Y}$ - negative sequence voltage vector at $\mathrm{ZS} X$ caused by transmission line $\mathrm{Y}$.

Then the percentage contribution from line $\mathrm{Y}$ at ZS X can be quantified using (14). Fig. 7 illustrates the results of this evaluation process which reveals that lines F, I and A can be ranked $1^{\text {st }}, 2^{\text {nd }}$ and $3^{\text {rd }}$ respectively based on their overall contribution. The contribution from line $\mathrm{J}$ is negligible while line $\mathrm{D}$ is seen to have a negative contribution to the problem, although they introduce significant levels of influence on their own. In addition, among the identified minor sources of voltage unbalance lines $\mathrm{B}$ and $\mathrm{N}$ are seen to support the three leaders (lines F, I and A) to aggravate the problem, while other lines ( $\mathrm{C}, \mathrm{M}$ and $\mathrm{L})$ can be disregarded as far as the their contribution to the overall problem is concerned.

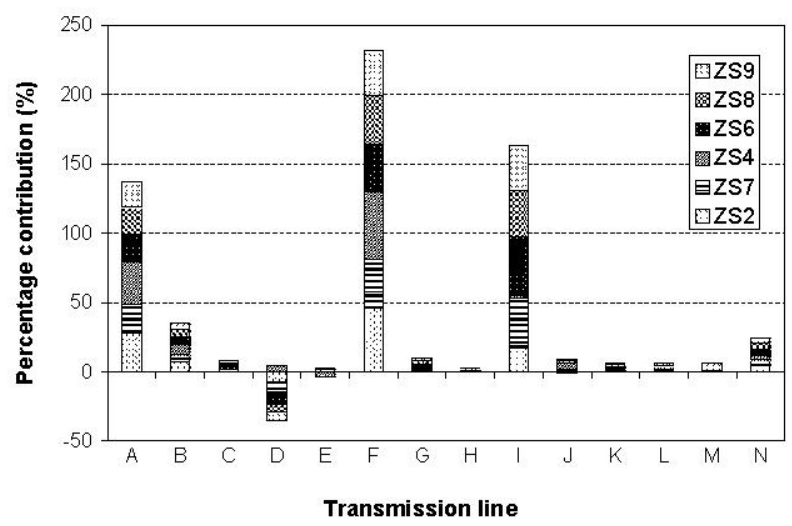

Fig. 7. Percentage contribution from individual transmission lines to negative sequence voltages at key ZSs

\section{CONCLUSIONS}

A generalised three-phase power flow program incorporating both load and network asymmetry has been developed in phase domain, which has been employed to investigate the role played by the asymmetry of transmission lines of a $66 \mathrm{kV}$ sub-transmission network in relation to voltage unbalance.

It has been identified that the asymmetry associated with the transmission lines is a primary source of voltage unbalance causing voltage unbalance levels up to $1.4 \%$ at some ZSs of the study network, which are above the code requirements.

The study presented reveals that $I_{+}$forced through an asymmetrical line governs the negative sequence current and 


$$
\text { Contribution from } Y \text { at } Z S X=\frac{\left|V_{2, Z S X / Y}\right| \cos \left(\theta_{Z S X / Y}-\theta_{Z S X}\right)}{\left|V_{2, Z S X}\right|} \times 100 \%
$$

hence the negative sequence voltage which essentially arise as a result of $Z_{-+}$. The primary determining factors of negative sequence power flow are $Z_{-+}$and $I_{+}$at light loading levels, and the influence of $Z_{++}$becomes significant at heavy loading conditions. The studies also reveal that the impedance $\left|Z_{-+}\right|$can be used to assess the degree of line asymmetry in relation voltage unbalance. Hence, lines M, I, F, A, and D of the study network can be identified as the most asymmetrical lines.

In an interconnected network environment $\left|Z_{-+}\right|$and $\left|I_{+}\right|$ of the transmission lines have been noted to be the primary factors which determine the influence of individual lines on voltage unbalance in general. Hence, transmission lines I, F, $\mathrm{A}, \mathrm{D}$ and $\mathrm{J}$ can be identified as the major sources of voltage unbalance in relation to the study network, while lines B, N, $\mathrm{C}, \mathrm{L}$ and $\mathrm{M}$ can be identified as the minor sources.

Employing the fact that the operation of the negative sequence network of the study system with balanced loading conditions is linear, an approach has been developed to quantify the contribution from individual transmission lines at nodal level to voltage unbalance. Using the results of this evaluation process, the major contributors to the problem of voltage unbalance in the study network has been identified as lines $\mathrm{F}, \mathrm{I}$ and $\mathrm{A}$.

The methodologies given in this paper can in general be applied to interconnected sub-transmission networks in relation to voltage unbalance studies.

\section{REFERENCES}

[1] System Standards, National Electicity Code Australia, Version 1.0 Amendment 9.0, S5.1a.7, October 2004.

[2] Electricity Distribution Code, Victoria, January 2002.

[3] Xiao-Ping Zhang and Heng Chen, 'Sequence-Decoupled NewtonRaphson Three-phase Load Flow', Proc. IEEE Region 10 Conf. on Computer, Communication, Control and Power Engineering, TENCON '93, Vol. 5, Issue 0, Part 50000, pp. 394 - 397, 19-21 Oct. 1993.

[4] M. A. Laughton, 'Analysis of Unbalanced Poly-phase Networks by the Method of Phase Co-ordinates', IEE Proc., Vol. 115, No. 8, Aug. 1968.

[5] M. Abdel-Akher, K. M. Nor and A. H. A. Rashid, 'Improved Threephase Power Flow Methods using Sequence Components', IEEE Trans. on Power Systems, Vol. 20, Issue 3, pp. 1389 - 1397, Aug. 2005.

[6] W. Xu, H. W. Dommel and J. R. Marti, 'A Generalised Threephase Power Flow Method for the Initialisation of EMTP Simulations', Int. Conf. on Power System Technology, POWERCON '98, Vol. 2, pp. 875-879, 18-21 Aug. 1998.

[7] W. Xu, J. R. Marti and H. W. Dommel, 'A Multiphase Harmonic Load Flow Solution Technique', IEEE Trans. on Power Systems, Vol. 6, Issue 1, pp. 174 - 182, Feb. 1991.

[8] Prabha Kundur, 'Power System Stability and Control', McGraw-Hill, Inc., pp. 271-274, 1993.
[9] Paul M. Anderson, 'Analysis of Faulted Power Systems', A John Wiley \& Sons, Inc., pp. 71-83, 1995.

[10] Prabodha Paranavithana, Sarath Perera and Danny Sutanto, 'Impact of Untransposed $66 \mathrm{kV}$ Sub-transmission Lines on Voltage Unbalance', Australasian Universities Power Engineering Conf. (AUPEC), Paper 28, Melbourne-Australia, Dec. 2006.

APPENDIX A
DECOMPOSITION OF NEGATIVE SEQUENCE
CURRENT VECTOR IN A TRANSMISSION LINE
CAUSED B Y ASYMMETRICAL TRANSMISSION
LINES

The resultant negative sequence current vector in a selected transmission line caused by the asymmetry of the network is equal to the vector addition of negative sequence current components caused by individual transmission lines in the selected line, as expressed by (A.1):

$$
I_{-, X}=\sum I_{-, X / Y}
$$

where,

$X$ - represents the selected transmission line

$I_{-, X}$ - resultant negative sequence current vector in transmission line $\mathrm{X}$

$Y$ - represents an asymmetrical transmission lines of the network

$I_{-, X / Y}$ - negative sequence current vector caused by transmission line $\mathrm{Y}$ in transmission line $\mathrm{X}$

The current $I_{-, X}$ can be obtained by three-phase power flow analysis when all transmission lines of the network are kept with their actual construction while the loads are balanced, and $I_{-, X / Y}$ can be obtained by keeping only $\mathrm{Y}$ with its actual construction while the other lines are hypothetically transposed and loads are balanced.

As an example, let $\mathrm{X}=\mathrm{I}$ and $\mathrm{Y}=\mathrm{A}, \mathrm{B}, . ., \mathrm{I}, . ., \mathrm{N}$. Then: $I_{-, I}=I_{-, I / A}+I_{-, I / B}+\ldots .+I_{-, I / I}+\ldots .+I_{-, I / N}$

Under the operating conditions considered (assuming balanced loads), the negative sequence current components introduced by individual transmission lines in line I are obtained as follows:

$I_{-, I / A}=1.1788-0.5771 j \mathrm{~A}$

$I_{-, I / B}=0.3155-0.1779 j \mathrm{~A}$

$I_{-, I / C}=-0.1009-0.2741 j \mathrm{~A}$

$I_{-, I / D}=0.2710+0.2745 j \mathrm{~A}$

$I_{-, I / E}=0.2812-0.0745 j \mathrm{~A}$

$I_{-, I / F}=1.7276-1.5954 j \mathrm{~A}$

$I_{-, I / G}=0.1657-0.2336 j \mathrm{~A}$

$I_{-, I / H}=0.0598-0.046 j \mathrm{~A}$

$I_{-, I / I}=-2.7817+2.6945 j \mathrm{~A}$

$I_{-, I / J}=0.5390+0.6502 j \mathrm{~A}$ 
$I_{-, I / K}=0.1000+0.0421 j \mathrm{~A}$

$I_{-, I / L}=0.0716+0.0415 j \mathrm{~A}$

$I_{-, I / M}=0.0063-0.0200 j \mathrm{~A}$

$I_{-, I / N}=0.0520-0.1036 j \mathrm{~A}$

Thus, $I_{-, I / A}+I_{-, I / B}+\ldots+I_{-, I / I}+\ldots+I_{-, I / N}=$ $1.8859+0.6006 j \mathrm{~A}$

The resultant negative sequence current vector in line I under same operating conditions is obtained as:

$I_{-, I}=1.7936+0.5671 j \mathrm{~A}$

Hence, the above results confirm the validity of (A.1).

\section{APPENDIX B \\ DECOMPOSITION OF NEGATIVE SEQUENCE VOLTAGE AT A ZS CAUSED BY ASYMMETRICAL TRANSMISSION LINES}

The resultant negative sequence voltage vector at a selected ZS caused by the asymmetry of the network is equal to the addition of negative sequence voltage vector components caused by individual transmission lines at the selected ZS, as expressed by (B.1):

$$
V_{2, Z S X}=\sum V_{2, Z S X / Y}
$$

where,

$Z S X$ - represents the selected ZS

$V_{2, Z S X}$ - resultant negative sequence voltage vector at ZS X

$Y$ - represents an asymmetrical transmission line of the network

$V_{2, Z S X / Y}$ - negative sequence voltage vector caused by transmission line $\mathrm{Y}$ at $\mathrm{ZS} \mathrm{X}$

The voltage $V_{2}, Z S X$ can be obtained by three-phase load flow analysis when all transmission lines of the network are kept with their actual construction while the loads are balanced, and $V_{2}, Z S X / Y$ can be obtained by keeping only $\mathrm{Y}$ with its actual construction while the other lines are hypothetically transposed and loads are balanced.

As an example, negative sequence voltage at ZS2 can be written as:

$V_{2, Z S 2}=V_{2, Z S 2 / A}+V_{2, Z S 2 / B}+\ldots .+V_{2, Z S 2 / N}$

Under the operating conditions considered (assuming balanced loads), the negative sequence voltage components introduced by individual transmission lines at ZS2 are obtained as follows:

$V_{2, Z S 2 / A}=58.560 \angle-127.176^{\circ} \mathrm{V}$

$V_{2, Z S 2 / B}=14.691 \angle-120.632^{\circ} \mathrm{V}$

$V_{2, Z S 2 / C}=12.124 \angle 151.737^{\circ} \mathrm{V}$

$V_{2, Z S 2 / D}=45.203 \angle-24.231^{\circ} \mathrm{V}$

$V_{2, Z S 2 / E}=4.401 \angle-139.636^{\circ} \mathrm{V}$

$V_{2, Z S 2 / F}=95.222 \angle-137.797^{\circ} \mathrm{V}$

$V_{2}, Z S 2 / G=0.950 \angle-134.214^{0} \mathrm{~V}$

$V_{2, Z S 2 / H}=0.257 \angle-119.429^{\circ} \mathrm{V}$

$V_{2, Z S 2 / I}=54.234 \angle 176.453^{0} \mathrm{~V}$

$V_{2, Z S 2 / J}=14.402 \angle-47.759^{\circ} \mathrm{V}$
$V_{2, Z S 2 / K}=1.850 \angle-75.263^{\circ} \mathrm{V}$

$V_{2, Z S 2 / L}=1.409 \angle-68.172^{\circ} \mathrm{V}$

$V_{2, Z S 2 / M}=0.361 \angle-170.834^{\circ} \mathrm{V}$

$V_{2, Z S 2 / N}=13.425 \angle 176.659^{\circ} \mathrm{V}$

Thus,

$V_{2, Z S 2 / A}+V_{2, Z S 2 / B}+\ldots+V_{2, Z S 2 / N}=$ $207.735 \angle-133.968^{\circ} \mathrm{V}$

The resultant negative sequence voltage vector at ZS2 under same operating conditions is obtained as: $V_{2, Z S 2}=205.703 \angle-134.344^{0} \mathrm{~V}$

Hence, the above results confirm the validity of (B.1). 